\title{
A Quarter Century of Emerging Infectious Diseases - Where Have We Been and Where Are We Going?
}

\author{
James W. Le Duc ${ }^{1}$, Teresa E. Sorvillo²
}

${ }^{1}$ Galveston National Laboratory, University of Texas Medical Branch, Galveston, Texas, USA, ${ }^{2}$ Department of Microbiology and Immunology, University of Texas Medical Branch, Galveston, Texas, USA

Correspondence: jwleduc@utmb.edu Tel.: + 4092666500

Fax.: + 4092666810

Received: 20 October 2017

Accepted: 7 February 2018

Key words: Emerging Diseases - Public Health Policy - Globalization - Economic Development - Advances in Biotechnology. health preparedness.
A quarter century ago the landmark report from the U. S. National Academies of Sciences, Engineering, and Medicine entitled "Emerging Infections, Microbial Threats to Health in the United States" was released. This classic study captured the societal changes then underway in our rapidly growing world: The growth of the world's population and changing human behavior; the advances and globalization of technology and industry; the changes in economic development and land use; the dramatic increase in speed and frequency of international travel and commerce; the adaptation of microbes and the appearance of never before seen pathogens; and the breakdown of traditional public health measures. This societal evolution has only increased and the growing frequency of outbreaks foretold in the report has come to pass. Each new disaster has precipitated changes and adaptations in our global response to infectious diseases designed to reduce risks and avoid future outbreaks. We discuss these past events and how each led to change in an effort to mitigate future threats. We also look to the future to consider what challenges might lay ahead. Conclusion. Major outbreaks over the past quarter century validated the concept of emerging infectious diseases and led to improvements in global policies and national public health programs; however, there will likely always be new diseases and the threat of reemergence of diseases once thought controlled leading to a constant need for vigilance in public

\section{Introduction}

The 1992 publication by the United States National Academies of Sciences, Engineering, and Medicine (NASEM) entitled "Emerging Infections: Microbial Threats to Health in the United States" was a watershed event that captured the many societal changes taking place around the world that impacted human health and resulted in the christening of a new term, "emerging infectious diseases" which continues to be relevant even now, a quarter century later
(1). The speed of international travel and commerce coupled with advances in technology, increases in the world's population, changes in human behavior, expansion of communities into areas previously uninhabited thereby bringing people into close contact with zoonotic pathogens, and a general breakdown in public health had all combined to set the stage for recognition of diseases hitherto unknown and the emergence of resistant microbes resulting from microbial adaptations. The discovery of HIV/ 
Table 1. Selected outbreaks and technological advances of international importance that validate the concepts of Emerging Infections, 1992 to the present

\begin{tabular}{l}
\hline Notable Outbreaks, 1992-1995 \\
\hline Hantavirus in the Americas, 1993 \\
Plague in Surat, India, 1994 \\
Hendra virus in Australia, 1994 \\
Ebola Hemorrhagic Fever, Kikwit, DRC 1995 \\
\hline Notable Outbreaks, 1996-2005 \\
\hline Avian influenza in Asia, 1997 \\
Nipah virus in Malaysia, 1999 \\
West Nile virus in USA, 1999 \\
Anthrax mailings in USA, 2001 \\
SARS in Asia, 2002-2003 \\
Monkeypox in USA, 2003 \\
\hline Notable Outbreaks and technological advances, 2006-present \\
\hline Foodborne Outbreaks \\
Avian Influenza \\
Emergence of Chikungunya, dengue, yellow fever and Zika viruses \\
Crimean-Congo hemorrhagic fever, severe fever with thrombocytopenia, heartland viruses \\
Ebola in West Africa, 2014-2016 \\
\hline
\end{tabular}

AIDS, the isolation of Hantaan virus as the cause of Korean hemorrhagic fever in Korea and epidemic hemorrhagic fever in China, and the discovery of hepatitis $\mathrm{C}$ virus were among newly recognized pathogens that set the stage for Emerging Infections and served as a prelude for the many new diseases that were to be discovered in the coming quarter century. Here we note some of the more significant new pathogens discovered and the notable outbreaks that led to advances in global policies and technologies to address these emerging threats (Tables 1 and 2).

\section{Notable Emerging Infectious Diseases, 1992-1995}

Hantavirus in the Americas, 1993. In May of 1993 an outbreak of a previously unknown disease was reported in the southwestern United States (2). This rapidly fatal illness was primarily seen among rural, previously healthy young men and after considerable investigation was determined to be caused by a novel virus later named Sin Nombre virus. This new virus was shown to be related to Hantaan virus, the cause of hemorrhagic fever with renal syndrome, previously found only in Asia and Europe. The disease caused by the new virus was named Hantavirus Pulmonary Syndrome (or now Hantavirus Cardiopulmonary Syndrome) (3). Patients typically suffered from acute shortness of breath and often died very rapidly, even when hospitalized (4). Hantaviruses are frequently associated with rodent hosts, and subsequent investigations found Sin Nombre virus to be harbored by wild deer mice (5). As studies continued, additional New World hantaviruses were discovered from a variety of rodent hosts and many of these new viruses were shown to cause similar life-threatening human infections. The discovery of a completely new group of viruses within the United States and throughout the Americas causing fatal human infections 
drew considerable attention in the popular press and was an early validation of the concept of "Emerging Infectious Diseases."

Plague in Surat, India, 1994. Between August and October of 1994, an outbreak of bubonic and pneumonic plague struck the Indian city of Surat (6). Discovery of this historic disease in a major urban center of India triggered widespread panic and about 300,000 people left the city over the course of a few days. The resulting crisis led to flight cancelations and blockage of imports from India. The economic impact of the outbreak far exceeded the real human toll of a little over 50 deaths but it made a significant impression on the global community as clear demonstration of the potential magnitude of a public health crisis (7).

Hendra Virus in Queensland, Australia, 1994. A small outbreak near Brisbane, Australia in 1994 led to the death of a horse trainer and some of his horses and resulted in the discovery of Hendra virus (8). This was an absolutely new virus, completely unknown to science yet capable of killing both horses and humans (9). While the number of infections was not great, the fact that a novel virus had been discovered captured the interest of the general public and the scientific community. This was yet another example of an emerging infectious disease.

Ebola Hemorrhagic Fever, Kikwit, DRC, 1995. Ebola virus was first discovered in 1976 and was associated with a devastating outbreak in central Zaire (now Democratic Republic of the Congo) and nearly simultaneously in a second outbreak near the border between Zaire and Sudan (10, 11). The outbreaks were caused by distinct viruses now termed Ebola Zaire and Ebola Sudan, but both caused human disease with very high case fatality rates and little options for treatment. Following these original outbreaks, only isolated cases were reported until a major outbreak of Ebola Zaire occurred in Kikwit, DRC (12). The outbreak followed the pattern seen earlier with very high mortality rates, with an especially devastating impact on the healthcare infrastructure. Unlike the original Ebola outbreaks that occurred in remote locations with difficult access and poor communications, the Kikwit outbreak was reported in near real-time to a global audience (13). For the first time, the world could read about the unfolding tragedy and see photos from the actual outbreak site. As a result, the name Ebola became part of our vocabulary as the cause of one of the most dangerous diseases ever known.

\section{Impact}

These outbreaks, all well documented in the popular press, gave witness to the validity of the observations made in the NASEM report - that emerging infectious diseases were a part of modern life and that they demanded a new, more agile approach to their recognition and control. In the United States, the Centers for Disease Control and Prevention (CDC) had initiated a new program to implement the recommendations suggested in the NASEM report and one facet was to engage with the World Health Organization (WHO) in an effort to coordinate actions globally. The result was the development and acceptance of two World Health Assembly resolutions relevant to emerging diseases: WHA48.7 Revision of the International Health Regulations and WHA48.13 New, Emerging and Re-Emerging Infectious Diseases (14). Together these resolutions set in motion the creation of a new program to address emerging diseases by the WHO and the development of the revised International Health Regulations which was finally accepted in 2005 and implemented in 2007. These and other actions set the foundation for WHO's engagement in emerging infectious diseases that continues to this day. 
Notable Infectious Diseases, 1996-2005

Nipah Virus in Malaysia, 1999. Nipah virus was first isolated as part of an outbreak of encephalitis and respiratory disease seen primarily in commercially raised pigs and in pig farmers (15). Nearly 300 human infections were seen with over 100 deaths and more than one million pigs were euthanized to control the outbreak (16). Nipah and Hendra viruses are closely related and studies of each found large flying fox (Pteropus) bats as the likely reservoir host $(17,18)$. Cases of Nipah are now recognized most years among rural residents of Bangladesh. The significance of this outbreak was not only the discovery of yet another new virus disease with the ability to kill both humans and domestic animals, but also the tremendous economic impact that the outbreak had on the agricultural sector.

West Nile Virus Introduced into the United States, 1999. West Nile virus is a mosquito-borne pathogen that has long been recognized to cause illness and occasional death in humans and animals in various countries of Asia and Africa, but until its introduction in Queens, New York in 1999, it had never been found in the Americas (19). West Nile virus found a very receptive environment in the United States with competent mosquito vectors and susceptible vertebrate populations. Over the course of the following decade the virus marched across the continental United States and expanded its range into Central and South America such that today it is found in most countries of the Americas. It has caused thousands of severe neurological cases in humans and hundreds of fatalities, mass mortality among birds, especially crows, and encephalitis in horses, all primarily in the United States but also throughout the Americas (20). The significance of this outbreak was its demonstration of the receptivity of new ecological environments to the introduction of exotic pathogens, the difficulty in controlling vector-borne diseases, and the significant impact that introduced pathogens can have on human health, wildlife and agriculture.

Anthrax Mailings, United States, 2001. Shortly after the terrorist attacks of September 11, 2001, a number of letters containing anthrax spores were sent to various individuals including political leaders and news organizations resulting in five deaths and 17 others infected (21). Anthrax had been previously weaponized as a biological warfare agent and its ability to cause serious and fatal disease following aerosol exposure was well known, but its intentional use as a terrorist weapon disseminated by the postal service was a stark warning of the potential misuse of modern biology (22). Here was an emerging disease of manmade origin. This event triggered a massive increase in spending in the United States to protect the nation against bioterrorism and drew global attention to the potential for misuse of dangerous pathogens. While the United States select agent program was already in place when the anthrax mailing occurred, the event nonetheless heightened the need for enhanced security surrounding laboratories handling especially dangerous pathogens.

Severe Acute Respiratory Syndrome (SARS), Asia, 2002-2003. In late 2002 rumors surfaced that an outbreak of severe respiratory disease was underway in southern China. Shortly after the start of the new year a physician who had treated such cases travelled to Hong Kong, stayed briefly in a Hong Kong hotel, became ill and was hospitalized and later died. He became the index case of one of the most devastating outbreaks in recent memory (23). A highly contagious new coronavirus was shown to be the cause of the illness and was named SARS virus and over the following several months over 8000 cases occurred with nearly 800 deaths (24, 25 ). In addition to being a completely new virus to science, this outbreak was noteworthy by the speed with which it was dissemi- 
nated around the world, how cases emerged even in modern hospitals with excellent facilities and skilled clinical staff, and how unprepared the world really was to address a modern emerging infectious disease. Historic concepts of public health control such as quarantine and patient isolation had to be adapted to modern society.

Monkeypox Virus, United States, 2003. Monkeypox virus is related to smallpox and is found in Central and West Africa where it is maintained in a zoonotic cycle involving squirrels and other rodents, occasionally spilling over to infect humans (26). In 2003 just as the SARS pandemic was subsiding, a febrile illness with rash was seen in a Wisconsin child following a bite by a pet prairie dog purchased from a local pet vendor. Subsequent investigations found Monkeypox virus as the cause and over 70 human cases were ultimately identified throughout the Midwest United States. Extensive investigations of the prairie dog revealed a complex network of formal and informal sales of exotic pets linking the prairie dogs to recently imported Gambian pouched rats from West Africa (27). The significance of this outbreak was discovery of the extensive movement of wild animals collected in rural Africa which were easily moved to the United States where they were sold as exotic pets without any regard to the diseases they might be harboring. Subsequent policy changes were implemented to prevent the importation of some species of rodents from Africa and the sale and distribution of prairie dogs.

\section{Impact}

The outbreaks and epidemics of this decade, in addition to providing yet more examples of new diseases arising around the world, also brought to light several shortcomings in existing policies that hampered the ability of health officials to adequately address emerging infectious diseases of global im- portance. The SARS epidemic perhaps more than any other event demonstrated the severe economic toll that infectious diseases can impose on the global economy. Further, it highlighted the challenges of information sharing internationally, and the need for modern interpretation of mitigation strategies that allow quarantine of those exposed and isolation of infected patients suffering from a highly communicable disease. The monkeypox outbreak clearly demonstrated the importance of zoonoses to global health and the need for improved regulations to protect unsuspecting consumers from exposure to zoonotic pathogens. In 1999, prior to the anthrax mailings, the United States federal government by way of the CDC spearheaded the creation of the Laboratory Response Network (LRN), a defined network of laboratories within the United States and abroad with the capacity to rapidly respond to biological, chemical, or radiological threats via timely diagnostic testing and secure result notifications. One of the early successes of the LRN was its role in aiding with the rapid identification of $B$. anthracis from the 2001 anthrax letters. The anthrax mailings were nonetheless a stark reminder of the power of pathogens as potential weapons and the need for further safeguards surrounding the safe and secure handling of these agents. This decade of emerging infections also resulted in the final agreement on the revised International Health Regulations which placed new emphasis on WHO's role in outbreak response, improved public health laws to govern outbreak interventions taken by health officials, and increased regulation of the exotic pet industry.

\section{Notable Infectious Diseases, 2006 - Present}

Foodborne Outbreaks. With the globalization of the food supply has come more complex outbreaks of foodborne illnesses. Major 
outbreaks caused by hepatitis A virus, toxigenic E. coli, listeria and others have been publicized in the popular press and resulted in many human infections (28). The commercial food producers, importers, suppliers and consumers have worked closely with public health officials to improve production techniques, better track products and recognize outbreaks earlier so that effective interventions can be made rapidly and future risks mitigated.

Avian Influenza. Influenza viruses, especially influenza A viruses, are the classic example of an emerging infectious disease. Influenza A H1N1 and $\mathrm{H} 3 \mathrm{~N} 2$ viruses circulate, along with influenza B viruses, among humans every year. These viruses evolve through antigenic shift and drift to create new strains that may avoid existing protective immunity among humans and may cause pandemics as was seen during the 2009 pandemic of a novel influenza A H1N1 virus that rapidly spread around the world over the course of a few months (29). Lurking silently is a vast array of other zoonotic influenza viruses that may cause disease and death in animals and may mutate or recombine to form a virus transmissible among humans. For the past decade and more there has been growing concern about the possibility of a major pandemic of influenza and considerable investment has been made to improve global surveillance of influenza viruses circulating in both humans and animals, promptly stomp out emerging outbreaks among animals, and improve national preparedness in the event of a pandemic. The rapidity of spread of the 2009 novel H1N1 influenza A virus clearly demonstrated weaknesses in global preparedness efforts and the need for continued work to improve global surveillance, enhance vaccine production and distribution, and revise preparedness planning.

Chikungunya, Dengue, Yellow Fever and Zika Viruses. These viruses share the com- mon characteristic of being transmitted by the urban mosquito vector, Aedes aegypti. Once nearly controlled in many parts of the world, Ae. aegypti is now found in most urban centers of the tropics and subtropics around the world (Figure 1). The mosquito has adapted to live in close association with humans and is a competent vector of many viruses (30). Introductions of "new" viruses such as Chikungunya and Zika into New World habitats have resulted in thousands of human infections and the unfolding crisis of children being borne with severe disabilities following Zika infection during pregnancy (31). This has occurred against a backdrop of periodic major epidemics of any of the four dengue serotypes now circulating in many communities. The combination of urban growth, rapid travel, poverty and eroding sanitation coupled with the mosquito's ability to easily co-exist with humans has resulted in difficult challenges in vector control and disease prevention. The threat of not only newly emerging viruses to cause vector-borne outbreaks, but also the risk of urban transmission of often fatal yellow fever virus represents a major challenge to health in many corners of the world.

Crimean Congo Hemorrhagic Fever, Severe Fever with Thrombocytopenia, Heartland and Powassan Viruses. Similar to the growing importance of mosquito-borne pathogens, the dramatic rise of tick-borne pathogens is concerning. New viruses such as severe fever with thrombocytopenia virus, a tick-borne virus recently discovered in China, Heartland virus recently found in the United States, and classic viruses such as Crimean Congo hemorrhagic fever virus and Powassan virus are all examples of viruses that are either newly discovered or that have been known for many years but are only recently gaining the attention of public health officials due to their increased incidence and serious disease following infections (33). It is not clear if the rise in tick- 

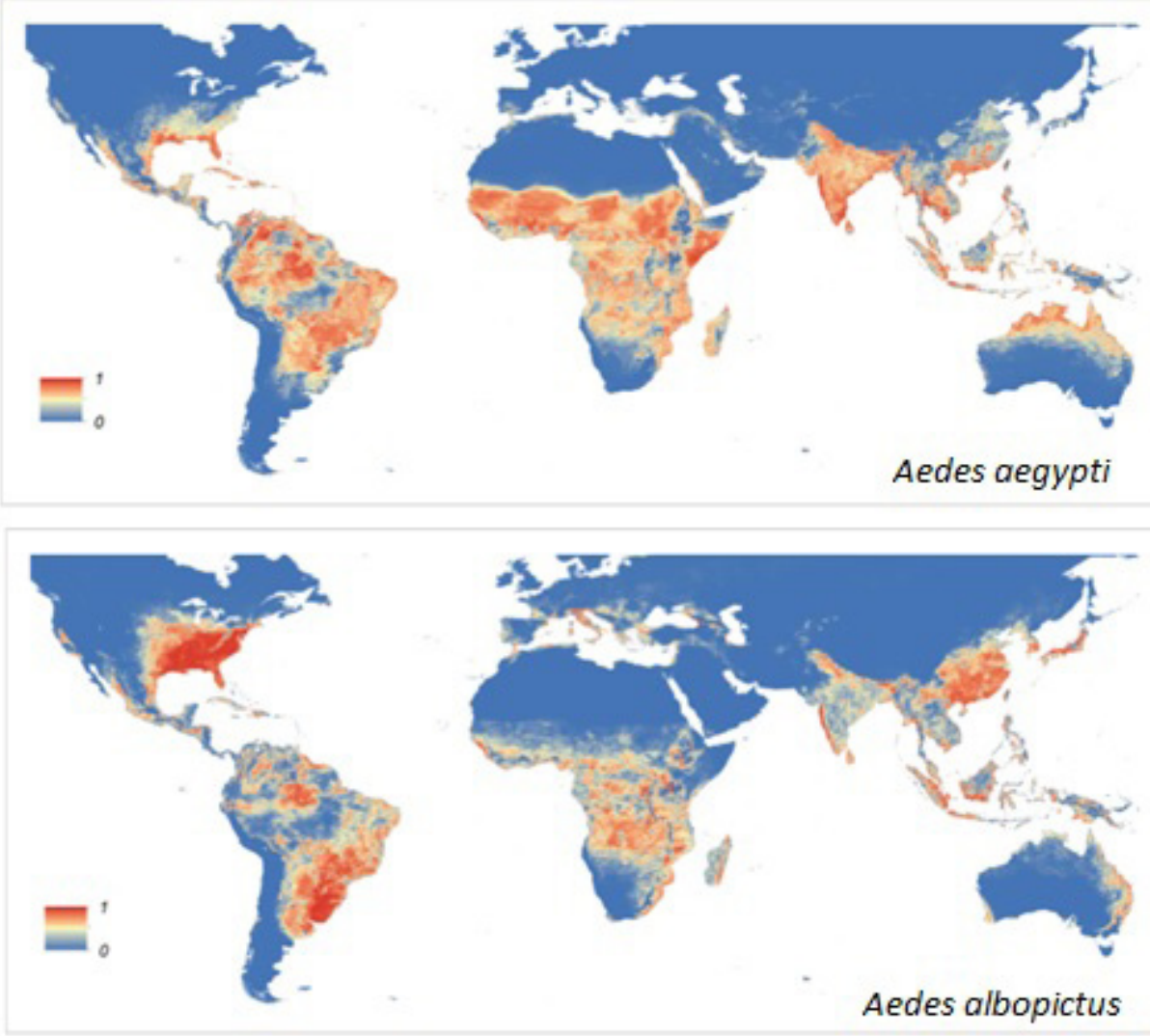

Figure 1. Global distribution of Aedes mosquitoes of public health importance. Estimated Aedes aegypti and Aedes albopictus distribution globally based on high (red) or low (blue) probability of habitation (32).

borne pathogens is the result of improved surveillance and better laboratory capabilities, or an increase in the abundance of ticks and their pathogens due to environmental changes and human population growth. Regardless, it is clear that tick-borne diseases have increased in prevalence and are likely to continue to do so, undoubtedly leading to the discovery of additional new emerging infectious diseases.

Ebola Virus, West Africa, 2014-2016. The Ebola outbreak of 2014-2016 was the nightmare scenario many public health officials had dreaded-a highly pathogenic, easily transmissible disease introduced into an urban center lacking adequate health care infrastructure or the ability to rapidly and effectively interrupt transmission (34).
The outbreak resulted in over 28,000 cases and over 11,000 deaths, most of which occurred in Liberia, Sierra Leone and Guinea. Cases were, however, exported to surrounding countries in Africa and to various distant countries including the United States, the United Kingdom, and others. The outbreak clearly demonstrated many of the concerns originally raised in the NASEM report-the importance of zoonotic infections and the risks they represent to human health, the importance in global travel as a potential disseminator of infections, the impact of population growth and urbanization coupled with poverty, and the need for global coordination in responding to such outbreaks (Figure 2). 


\section{Global airline traffic trends}

Analysis by Amadeus and its partner airconomy reveals that Asia Pacific, the Middle East and Europe have become hot spots for inter-regional airline traffic. The BRIC countries are also global drivers of growth in aviation

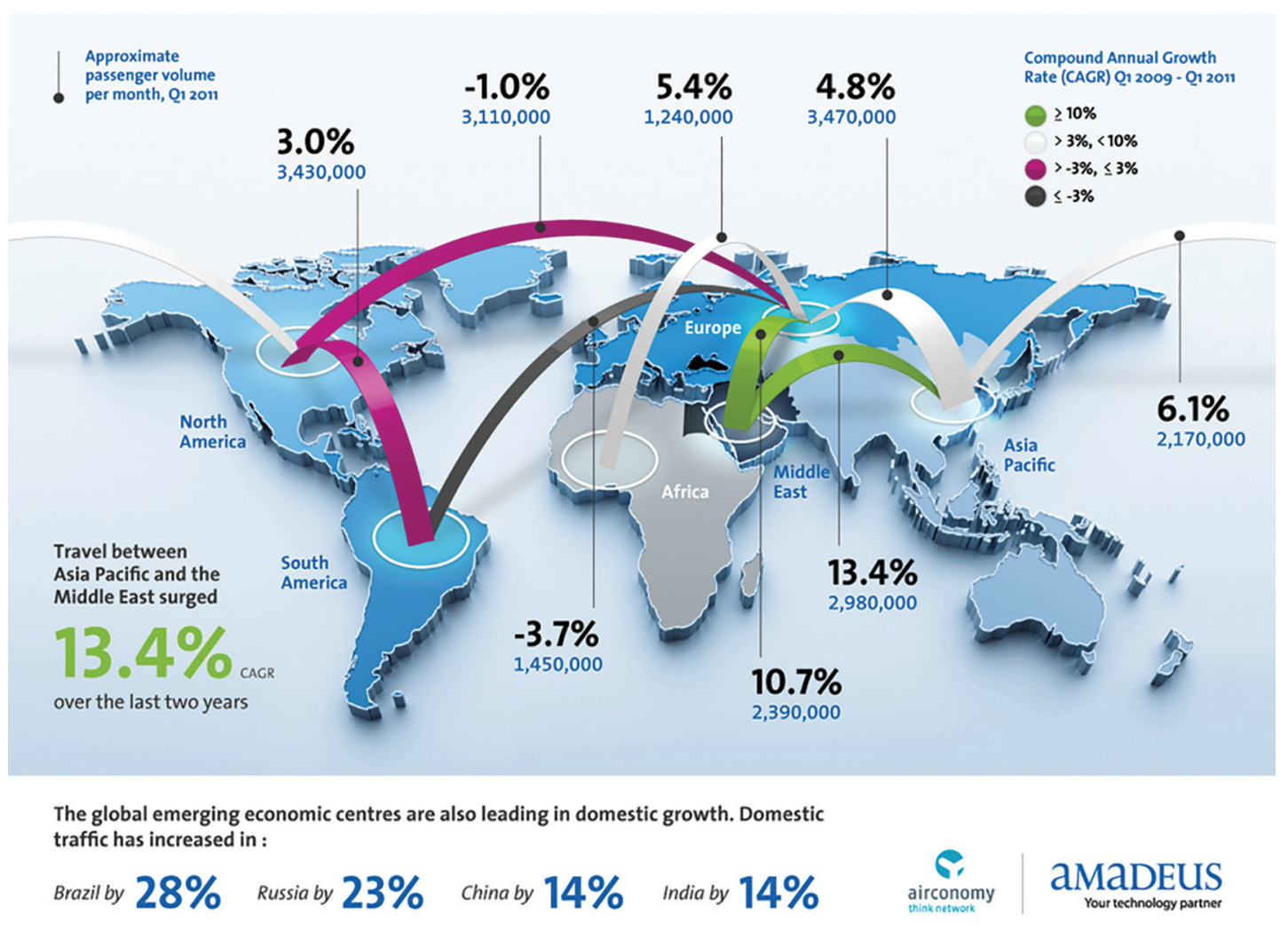

Figure 2. Global Airline Traffic Trends (35).

\section{Impact}

These and other events involving emerging infectious diseases have only served to heighten awareness amongst health officials and the general public that "new" diseases will continue to occur with some regularity. The rapidity of their spread has been facilitated by our modern international travel network that allows anyone to reach almost any place in the world in less that the incubation period of virtually all infectious diseases (Figure 2). This was dramatically demonstrated when a traveler from West Africa entered into the United States while asymptomatically incubating Ebola virus (36). The patient was carefully screened on arrival and found free of symptoms, yet a few days after landing in Dallas, Texas, he was seen at a local hospital, sent home initially, and only later hospitalized and diagnosed as an Ebola patient. Unfortunately, the patient died and two nurses providing care for him were infected themselves. The entire event reinforced the adage that an infectious disease outbreak anywhere is a threat everywhere.

The increased attention to the risk of pandemic influenza resulted in significant investments to improve global surveillance of influenza in several ways, including the establishment of national influenza centers in many countries, the rapid characterization of circulating viruses, and the sharing of surveillance information with the WHO to improve the composition of seasonal influenza vaccine. In addition, much greater awareness of avian influenza resulted in vastly improved global information sharing and 
Table 2. Global impact and response to outbreaks of emerging infectious diseases, 1992 to the present

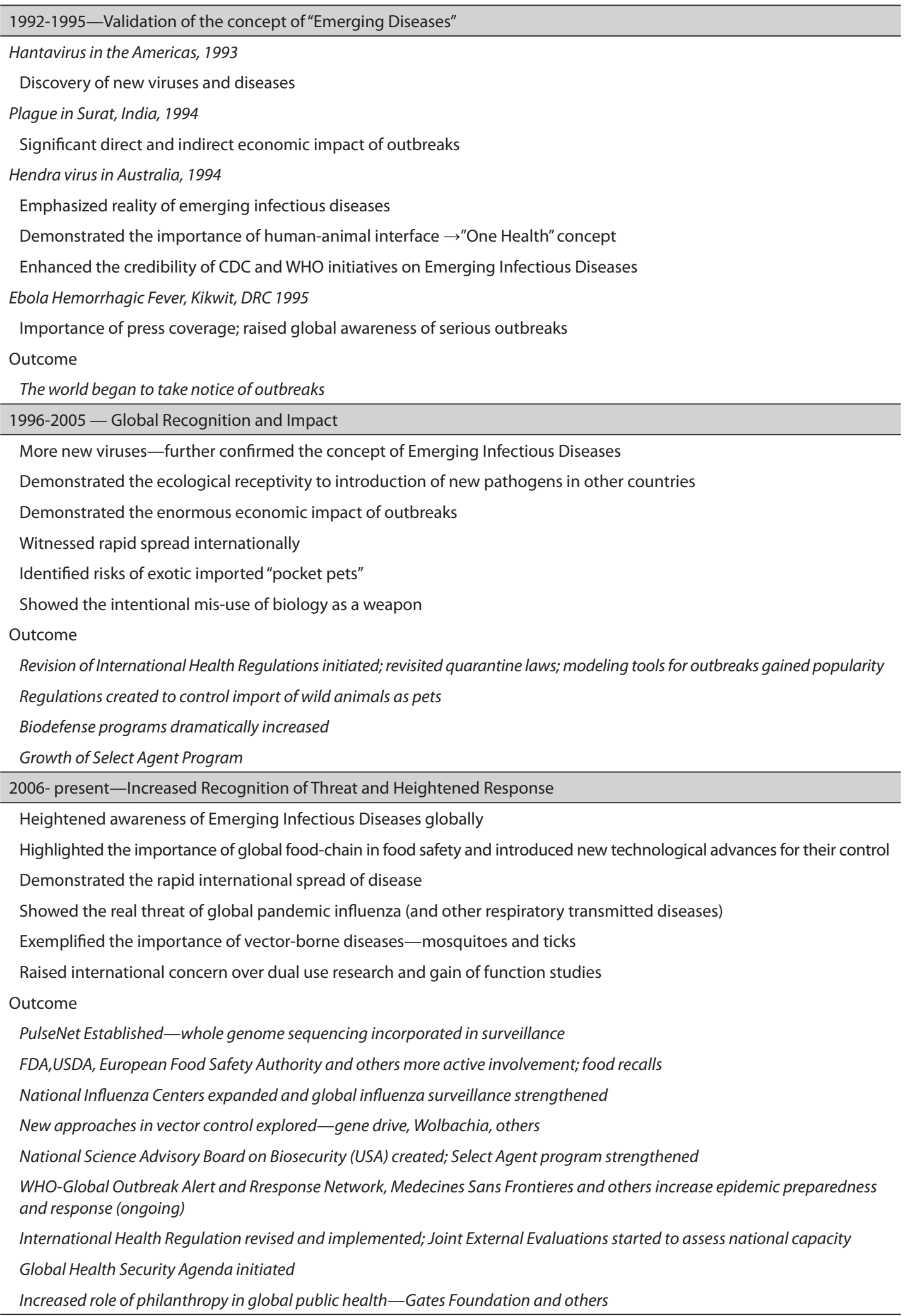


coordinated control efforts especially in China and other countries in Asia where avian influenza is prevalent. Greater recognition is now being paid to vectors and vector control, with modern biotechnology being used to engineer lethal mutations in mosquito vectors and the first real novel approaches to the control of Ae. aegypti mosquitoes in decades (37). Unfortunately, similar progress has yet to be made in the control of vector ticks.

The past decade of emerging infections has served to highlight the synergism of human, animal and environmental factors in impacting public health, resulting in the creation of the One Health initiative in 2008. The initiative recognizes that the majority of new emerging infections are zoonotic and works to foster multidisciplinary collaborations in order to advance the health of all species and their environment.

\section{Technological Advances in the Past Quarter Century}

In the early 1990s email was starting to be more widely used internationally, the internet was growing, and the internet-based disease reporting system ProMED, the Program for Monitoring Emerging Diseases was launched. Social media was not yet popular, but it was clear that a revolution in information sharing was underway and that it was increasingly difficult for outbreaks of disease to escape international recognition. This trend only increased in ensuing years and it became apparent that the International Health Regulations of 1969 were no longer appropriate for the modern, interconnected society and, as indicated above, the process to revise the regulations began in 1995, was approved internationally in 2005, and the new regulations are now in place. Many changes resulted from the revisions, including placing greater demand on countries to build their own core capacity to recognize and respond to disease threats and providing $\mathrm{WHO}$ with greater flexibility to respond to outbreaks of international significance. This process is still evolving, but it is clear that major outbreak responses today involve a wider array of players including Medicine Sans Frontier (MSF), the European Centers for Disease Control (ECDC), the US Centers for Disease Control and Prevention (CDC) and many others. Further, countries like China have established their own internal CDCs that provide much improved surveillance, diagnosis, and response to emerging infectious diseases. Finally, the appearance of major philanthropic organizations such as the Bill and Melinda Gates Foundation have greatly impacted global health through targeted investments and capacity building internationally.

As indicated, today many of us enjoy fresh fruits and produce any time of the year, independent of the seasons. This is the result of a growing international network of growers and rapid transportation. Many advances have helped to improve our food supply and distribution network. Parallel advances have been made in technology such as PulseNet and more recently genomic sequencing that allows public health officials to rapidly characterize pathogens and track foodborne outbreaks nationally and internationally. Similarly, advances in diagnostic technology have transitioned from classic culture techniques to molecular-based identification and genomic "finger printing" of pathogens, often available in hours rather than days to weeks. In some cases, these assays are even available as point of care tests.

Over the past quarter century a much greater awareness has evolved regarding the importance of biosafety and biosecurity surrounding pathogens, especially those like anthrax that were previously weaponized. One result was the creation of the select agent program in the United States, designed to limit the distribution of dangerous pathogens to known entities and appropriately trained and screened individuals. This has consolidated research on dangerous pathogens and spurred the construction of 
biocontainment laboratories in the United States and abroad. The proliferation of biocontainment laboratories in theory allows research to be conducted more safely and securely; however, the cost of operations and the complexity of the facilities may become burdensome. Further, experimentation that involves changing the characteristics of pathogens such as the recent avian influenza gain-of-function (GOF) studies may result in added risk or even the threat of accidental release and creation of a pandemic (38). Modern biotechnology has also been used to recreate an extinct virus, horsepox, an accomplishment that raises serious questions about the possible construction of more dangerous viruses such as smallpox (39). Clearly many, many important advances are being made through biotechnology that benefit all humankind; however, the risk of misuse or accidental release is an unwelcome cost that cannot be ignored.

\section{Where Are We Going? Challenges and Opportunities of the Future}

No one can foretell the future, but one thing is clear: The emergence of new pathogens that we have witnessed over the past quarter century will continue to occur, only faster and with a bigger impact. Faster because we and our "things" are moving faster, more fre- quently and further distances than ever before. Bigger because there are more of us, we live in bigger urban centers, and we coexist closer together than at any time in history. Our warming world will impact us in many ways yet to be fully realized, but it's clear that vectors of disease are likely to be more abundant and more widely distributed. Advances in biotechnology and synthetic biology will create new products and improve health, perhaps even eliminating some devastating inherited diseases for generations to come. We would be wise, however to be cautious as we employ these new tools in biology.

What are the greatest threats to become the next emerging disease? It's impossible to predict, but four areas deserve our increased attention (Table 3):

Respiratory Transmitted Viruses. We know that seasonal influenza viruses are continually evolving and that every season we are faced with the threat of a new strain. We have also monitored avian influenza, watching for the emergency of a strain easily transmitted among people. These clearly should remain a focus of our attention, but we should not ignore the fact that there are other virus diseases that are easily transmitted by the respiratory route and may emerge at any time. The coronaviruses are a prime example based on our experiences with

Table 3. Potential Threats to be the Next "Emerging Diseases"

\begin{tabular}{l}
\hline Respiratory Transmitted Viruses \\
\hline Influenza A viruses, both seasonal and avian influenza-H7N9 currently greatest concern \\
Coronaviruses and other respiratory infections yet to be recognized \\
\hline Vector-borne viruses \\
\hline Viruses transmitted by Ae. aegypti of special concern_-Yellow fever (due to shortage of vaccine); perhaps Mayaro virus; \\
other vectors following the West Nile model—Japanese encephalitis \\
Tick-borne pathogens—-several “new" viruses recently discovered with others likely as temperatures warm and tick \\
ranges expand; rickettsial diseases; Lyme disease \\
\hline Repeat of Ebola scenario \\
\hline Easily transmitted dangerous pathogen in over-populated areas with poor health infrastructure (Marburg, Ebola Sudan) \\
\hline "Bio-Errors" \\
\hline Laboratory generation of extinct viruses; gain of function experiments; mis-use of synthetic biology
\end{tabular}


SARS, and the smoldering situation with MERS in the Middle East.

Vector-Borne Viruses. As mentioned already, the re-infestation of many communities where Ae. aegypti had been eliminated previously and its introduction into new geographic areas, coupled with its remarkable ability to thrive in urban and suburban environments, sets the stage for potential widespread transmission of a number of well-known arboviruses like dengue and yellow fever viruses as well as others not commonly known but potentially of great public health importance. Chikungunya and Zika viruses have emerged recently, and many experts think that Mayaro virus may be next (40). Ae. albopictus shares many of the same vector characteristics as Ae. aegypti but has a wider host range and geographic distribution and may serve as an important secondary vector for many arboviruses. The current shortages of yellow fever vaccine are especially disconcerting given the enzootic nature of yellow fever virus in many tropical countries and the potential for large urban outbreaks. Many species of ticks are efficient vectors of disease and in recent years we have seen several new viruses identified, some of which like severe fever with thrombocytopenia virus recently discovered in China, are highly pathogenic and much more widely distributed than originally thought. Other well-known viruses such as Crimean-Congo hemorrhagic fever virus have increased dramatically in some parts of their distribution. Tick abundance and the factors that affect tick-borne diseases are not well understood and they are likely influenced by a number of factors including land use, human encroachment and perhaps changing environmental conditions. Regardless of the core drivers, it is likely that we will see additional new tickborne diseases in the years to come.

Repeat of the Ebola-West Africa Scenario. The conditions that allowed Ebola virus to cause the horrific outbreak witnessed in
2014-16 are little changed today as compared to when the first case was introduced into the local urban settings. We know that highly virulent filoviruses continue to exist in silent zoonotic transmission cycles in nature in tropical Africa and perhaps elsewhere, and the massive urban centers across Africa with limited healthcare infrastructure and widespread poverty grow annually. The level of international trade and travel between African urban centers continues to expand, and while national governments and the international community have attempted to improve recognition and response capabilities in preparation of future outbreaks, there remains much to be done. The need for timely detection and control of the severe, life-threatening diseases caused by deadly pathogens such as Ebola is great and progress remains limited.

"Bio-Errors". Tremendous progress has been made through biotechnology to protect people from disease and improve the quality of life for millions around the world. This progress will undoubtedly continue; however, as technology improves and becomes more widely accessible, there is a very real possibility that mistakes may be made that could result in the creation or release of a known or novel pathogen that could cause serious disease or even start a pandemic. One significant risk are so-called "Gain of Function" studies that interrogate the molecular basis for transmissibility of pathogens with restricted host distribution like avian influenza. The proliferation of biocontainment laboratories around the world may help reduce the risk to the public, assuming that they are well maintained and employ appropriate safety and security precautions. Nonetheless, we should carefully consider the risks and benefits of studies that potentially modify the characteristics of microbes that may cause disease in humans or animals.

How do we ultimately address the emerging infections of tomorrow? Coordination 
of international responses and the rapid mobilization of resources will be paramount. In recognition of this, the WHO established the Global Outbreak Alert and Response Network (GOARN), a collaboration of institutions worldwide committed to rapid and coordinated responses to emerging infections. This and other WHO initiatives may serve to better coordinate the international response to future outbreaks, while continued efforts to build national and local capacity will be important to ensure rapid recognition of emerging threats and implementation of targeted interventions. In addition, advancement of research on emerging pathogens will be essential in combatting the next major public health threat. Importantly, in recent years, the number of high containment (biosafety level 3 and 4) laboratories throughout the world has increased significantly. Despite inherent concerns regarding best practices and safety regulations, these new laboratories may enable a larger swath of the population to pursue important research that may prevent emerging infections from becoming global threats.

\section{Conclusion}

As our world continues to evolve in the direction of advancing technology, human expansion, and climate change, so must our global discourse and response to the emerging infectious diseases that will undoubtedly continue to impact our world in the coming decades.

Authors' contributions: Both authors contributed equally to the preparation of this manuscript.

Conflict of interest: The authors declare that they have no conflict of interest.

Funding: NIH/NIAID 5UC7A1094660

\section{References}

1. Committee on Emerging Microbial Threats to Health, Division of Health Sciences Policy, Divi- sion of International Health, Institute of Medicine. Emerging Infections: Microbial Threats to Health in the United States. Washington (DC): National Academies Press (US); 1992.

2. Centers for Disease Control and Prevention [homepage on the Internet]. Tracking a Mystery Disease: The Detailed Story of Hantavirus Pulmonary Syndrome (HPS); c2012 [updated 2012 Aug 29; cited 2017 Jul 31]. Available from: https:// www.cdc.gov/hantavirus/outbreaks/history.html.

3. Elliott LH, Ksiazek TG, Rollin PE, Spiropoulou CF, Morzunov S, Monroe M, et al. Isolation of the Causative Agent of Hantavirus Pulmonary Syndrome. Am J Trop Med Hyg. 1994;51(1):102-8.

4. Duchin JS, Koster FT, Peters CJ, Simpson GL, Tempest B, Zaki SR, et al. Hantavirus Pulmonary Syndrome: A Clinical Description of 17 Patients with a Newly Recognized Disease. N Engl J Med. 1994;330(14):949-55.

5. Nerurkar VR, Song J, Song K, Nagle JW, Hjelle B, Jenison S, et al. Genetic Evidence for a Hantavirus Enzootic in Deer Mice (Peromyscus maniculatus) Captured a Decade before the Recognition of Hantavirus Pulmonary Syndrome. Virology. 1994;204(2):563-8.

6. Centers for Disease Control and Prevention (CDC). Human plague-India, 1994. MMWR Morb Mortal Wkly Rep. 1994;43(41):761-2.

7. Sivaramakrishnan K. The return of epidemics and the politics of global-local health. Am J Public Health. 2011;101(6):1032-41.

8. Wang LF, Michalski WP, Yu M, Pritchard LI, Crameri G, Shiell B, et al. A novel P/V/C gene in a new member of the Paramyxoviridae family, which causes lethal infection in humans, horses, and other animals. J Virol. 1998;72(2):1482-90.

9. Murray K, Selleck P, Hooper P, Hyatt A, Gould A, Gleeson L, et al. A morbillivirus that caused fatal disease in horses and humans. Science. 1995;268(5207):94-7.

10. Report of an International Commission. Ebola haemorrhagic fever in Zaire, 1976. Bulletin of the World Health Organization. 1978;56(2):271-93.

11. Report of a WHO/International Study Team. Ebola haemorrhagic fever in Sudan, 1976. Bulletin of the World Health Organization. 1978;56(2):247-70.

12. Centers for Disease Control and Prevention (CDC). Outbreak of Ebola Viral Hemorrhagic Fever -Zaire, 1995. MMWR Morb Mortal Wkly Rep. 1995;44(19):381-2.

13. Heymann DL, Barakamfitiye D, Szczeniowski M, Muyembe-Tamfum JJ, Bele O, Rodier G. Ebola hemorrhagic fever: lessons from Kikwit, Democratic Republic of the Congo. J Infect Dis. 1999;179(1):S283-6. 
14. Hardiman MC, World Health Organization Department of Global Capacities, Alert and Response. World Health Organization Perspective on Implementation of International Health Regulations. Emerg Infect Dis. 2012;18(7):1041-6.

15. Chua KB, Goh KJ, Wong KT, Kamarulzaman A, Tan PS, Ksiazek TG, et al. Fatal encephalitis due to Nipah virus among pig-farmers in Malaysia. Lancet. 1999;354(9186):1257-9.

16. Lam SK, Chua KB. Nipah Virus Encephalitis Outbreak in Malaysia. Clinical Infectious Diseases. 2002;34(2):S48-51.

17. Yob JM, Field H, Rashdi AM, Morrissy C, Van der Heide B, Rota $P$, et al. Nipah virus infection in bats (order Chiroptera) in peninsular Malaysia. Emerg Infect Dis. 2001;7(3):439-41.

18. Halpin K, Young PL, Field HE, Mackenzie JS. Isolation of Hendra virus from pteropid bats: a natural reservoir of Hendra virus. J Gen Virol. 2000;81(Pt 8):1927-32.

19. Centers for Disease Control and Prevention (CDC). Outbreak of West Nile-like viral encephalitis-New York, 1999. MMWR Morb Mortal Wkly Rep. 1999;48(38):845-9.

20. Gubler DJ. The Continuing Spread of West Nile Virus in the Western Hemisphere. Clin Infect Dis. 2007;45(8):1039-46.

21. Jernigan DB, Raghunathan PL, Bell BP, Brechner R, Bresnitz EA, Butler JC, et al. Investigation of Bioterrorism-Related Anthrax, United States, 2001: Epidemiologic Findings. Emerg Infect Dis. 2002;8(10):1019-28.

22. Meselson M, Guillemin J, Hugh-Jones M, Langmuir A, Popova I, Shelokov A, et al. The Sverdlovsk anthrax outbreak of 1979. Science. 1994;266(5188):1202-8.

23. Wong RS, Hui DS. Index Patient and SARS Outbreak in Hong Kong. Emerg Infect Dis. 2004;10(2):339-41.

24. Peiris JSM, Lai ST, Poon LLM, Guan Y, Yam LYC, Lim W, et al. Coronavirus as a possible cause of severe acute respiratory syndrome. The Lancet. 2003;361(9366):1319-25.

25. Centers for Disease Control and Prevention [homepage on the Internet]. Remembering SARS: A Deadly Puzzle and the Efforts to Solve; c2013 [updated 2013 Apr 26; cited 2017 Sep 1]. Available from: https://www.cdc.gov/about/history/sars/ feature.htm.

26. Di Giulio DB, Eckburg PB. Human monkeypox: an emerging zoonosis. Lancet Infect Dis. 2004;4(1):15-25.

27. Reed KD, Melski JW, Graham MB, Regnery RL, Sotir MJ, Wegner MV, et al. The Detection of Monkeypox in Humans in the Western Hemisphere. N Engl J Med. 2004;350(4):342-50.
28. Centers for Disease Control and Prevention [homepage on the Internet]. List of Selected Multistate Foodborne Outbreak Investigations; c2006 [updated 2017 Sep 14; cited 2017 Sep 1]. Available from: https://www.cdc.gov/foodsafety/outbreaks/ multistate-outbreaks/outbreaks-list.html.

29. Fineberg HV. Pandemic Preparedness and Response - Lessons from the H1N1 Influenza of 2009. N Engl J Med. 2014;370(4):1335-42.

30. Weaver SC, Charlier C, Vasilakis N, Lecuit M. Zika, Chikungunya, and Other Emerging Vector-Borne Viral Diseases. Annu Rev Med. 2018;69:395-408. Epub 2017 Aug 28.

31. Plourde AR, Bloch EM. A Literature Review of Zika Virus. Emerg Infect Dis. 2016;22(7):1185-92.

32. Kraemer MU, Sinka ME, Duda KA, Mylne AQ, Shearer FM, Barker CM, et al. The global distribution of the arbovirus vectors Aedes aegypti and Ae. albopictus. eLife. 2015 [cited 2017 Oct 9]; 4(e08347). Available from: https://www.ncbi.nlm. nih.gov/pmc/articles/PMC4493616/.

33. Mansfield KL, Jizhou L, Phipps LP, Johnson N. Emerging Tick-Borne Viruses in the Twenty-First Century. Front Cell Infect Microbiol. 2017;7:298.

34. Spengler JR, Ervin E, Towner JS, Rollin PE, Nichol ST. Perspectives on West Africa Ebola Virus Disease Outbreak, 2013-2016. Emerg Infect Dis. 2016;22(6):956-63.

35. Amadeus [homepage on the internet]. Infographics on the future of air travel 2011- latest travel trends, and potential airline industry trends; c2001 [cited 2017 Oct 9]. Available from: http:// www.amadeus.com/blog/13/12/a-year-in-infographics-travel-hot-spots-wireless-technologyand-frequent-flyer-miles/.

36. Chevalier MS, Chung W, Smith J, Weil LM, Hughes SM, Joyner SN, et al. Ebola virus disease cluster in the United States--Dallas County, Texas, 2014. MMWR Morb Mortal Wkly Rep. 2014;63(46):1087-8.

37. Harris AF, Nimmo D, McKemey AR, Kelly N, Scaife S, Donnelly CA, et al. Field performance of engineered male mosquitoes. Nat Biotechnol. 2011;29:1034-7.

38. Imai M, Watanabe T, Hatta M, Das SC, Ozawa M, Shinya K, et al. Experimental adaptation of an influenza H5 HA confers respiratory droplet transmission to a reassortant $\mathrm{H} 5 \mathrm{HA} / \mathrm{H} 1 \mathrm{~N} 1$ virus in ferrets. Nature. 2012;486(7403):420-8.

39. Kupferschmidt K. Labmade smallpox is possible, study shows. Science. 2017;357(6347):115-6.

40. Brunini S, França D, Silva J, Silva L, Silva F, Spadoni M, et al. High Frequency of Mayaro Virus IgM among Febrile Patients, Central Brazil. Emerg Infect Dis. 2017;23(6):1025-6. 